OPEN ACCESS

Edited by:

Dennis Murray,

Trent University, Canada

Reviewed by:

Jeffrey Ryan Row,

University of Waterloo, Canada

Robert Brian O'Hara,

BiK-F, Germany

*Correspondence:

Stewart L. Macdonald

stewart.macdonald@my.jcu.edu.au

Specialty section:

This article was submitted to

Population and Evolutionary

Dynamics,

a section of the journal

Frontiers in Ecology and Evolution

Received: 05 April 2017

Accepted: 18 July 2017

Published: 14 August 2017

Citation:

Macdonald SL, Llewelyn J, Moritz C and Phillips BL (2017) Peripheral Isolates as Sources of Adaptive Diversity under Climate Change.

Front. Ecol. Evol. 5:88. doi: 10.3389/fevo.2017.00088

\section{Peripheral Isolates as Sources of Adaptive Diversity under Climate Change}

\author{
Stewart L. Macdonald ${ }^{1,2 *}$, John Llewelyn ${ }^{1,2}$, Craig Moritz ${ }^{3}$ and Ben L. Phillips ${ }^{1,4}$ \\ ${ }^{1}$ Centre for Tropical Biodiversity and Climate Change, James Cook University, Townsville, QLD, Australia, ${ }^{2}$ CSIRO Land and \\ Water Flagship, Townsville, QLD, Australia, ${ }^{3}$ Centre for Biodiversity Analysis, Australian National University, Canberra, ACT, \\ Australia, ${ }^{4}$ School of Biosciences, University of Melbourne, Parkville, VIC, Australia
}

As climate change progresses, there is increasing focus on the possibility of using targeted gene flow (TGF, the movement of pre-adapted individuals into declining populations) as a management tool. Targeted gene flow is a relatively cheap, low-risk management option, and will almost certainly come into increased use over the coming decades. Before such action can be taken, however, we need to know where to find pre-adapted individuals. We argue that, for many species, the obvious place to look for this diversity is in peripheral isolates: isolated populations at the current edges of a species' range. Both evolutionary and ecological considerations suggest that the bulk of a species' adaptive variation may be contained in the total set of these peripheral isolates. Moreover, by exploring both evolutionary and ecological perspectives it becomes clear that we should be able to assess the potential value of each isolate using remotely sensed data and three measurable axes of variation in patch traits: population size, connectivity, and climatic environment. Locating the "sweet spot" in this trait space, however, remains a challenge. Throughout, we illustrate these ideas using Australia's Wet Tropics rainforests as a model system.

Keywords: assisted gene flow, climate change, local adaptation, geographic variation, targeted gene flow

\section{INTRODUCTION}

The reality of anthropogenic climate change is no longer in doubt. Climatic changes have already occurred (Jones et al., 1999; Meehl et al., 2007), and in biological systems there is mounting evidence that these relatively minor changes have already resulted in altered phenology, range shifts, and population declines (e.g., Parmesan, 2006; Freeman and Freeman, 2014). Much greater climate change lies in our immediate future (Meehl et al., 2007), and the impacts of this impending change are likely to be manifold and complex (e.g., Atkins and Travis, 2010; Norberg et al., 2012). Despite inherent uncertainties in how, exactly, climate change will play out, and how this will impact biodiversity (Moritz and Agudo, 2013), there are certainly grounds for deep concern regarding the future of many species (Thomas et al., 2004).

In the last decade or so, ecologists have moved from mounting arguments as to why climate change should be minimized/avoided (e.g., Flannery, 2006), to accepting the inevitability of a substantial change in climate, and pondering how the biodiversity impacts of that change might be mitigated. There now exist, for example, frameworks for assessing species' vulnerability to climate change (e.g., Williams et al., 2008), and various decision tools for determining appropriate 
management options (e.g., Shoo et al., 2011; Miller et al., 2012). For species that are clearly at high risk of extinction (e.g., many range-restricted species, especially mountain-top endemics; La Sorte and Jetz, 2010) it has been argued, albeit controversially, that extinction might be averted by assisted colonization; the movement of populations to areas outside the species' normal range (McLachlan et al., 2007; HoeghGuldberg et al., 2008). Although there may be a good case for assisted colonization in some circumstances, it is not without risks (Ricciardi and Simberloff, 2009). Assisted colonization also requires the identification of suitable habitat for the focal species-potentially difficult for rare and range-restricted taxa (i.e., the species at highest risk of extinction; McLachlan et al., 2007).

Another strategy for minimizing biodiversity loss, is targeted gene flow (TGF), wherein individuals are moved within their existing range to introduce specific adaptive traits into the recipient population (Hoffmann and Sgrò, 2011; Weeks et al., 2011; Aitken and Whitlock, 2013; Kelly and Phillips, 2016). If we think of climate change as having a velocity-the rate and direction that local climate moves across the earth's surface (Loarie et al., 2009; Sandel et al., 2011; VanDerWal et al., 2013) - then locally adapted genes need to keep pace with this velocity. It is clear that such local adaptation is already occurring (e.g., Umina et al., 2005; Lavergne et al., 2010), but for taxa that have long generation times, low reproductive rates, low genetic diversity, and/or low levels of gene flow, it might not be happening fast enough (Quintero and Wiens, 2013). Although complex to implement, TGF carries far fewer ecological risks than assisted colonization because species are not being introduced to new areas and ecological communities. Of course the genetic risks (e.g., outbreeding depression) of TGF still need to be considered.

The next several decades will likely see an increasing use of both assisted colonization and TGF. Indeed, community groups and government agencies are already performing both actions (e.g., Marris, 2009; Weeks et al., 2015), so the challenge might not be in having these actions performed, but rather in having them performed in a planned, strategic manner (e.g., HoeghGuldberg et al., 2008; Willis et al., 2009): although TGF is already happening, to our knowledge there are currently no wellreported and monitored case studies. Whether the intent is TGF or assisted colonization, however, it is clear that the presence of appropriate adaptive variation in the source population is important. Assisted colonization efforts risk failure if the introduced individuals are maladapted to the release locality; TGF requires the identification of adaptive variation suited to the future climate of the intended release localities. Locating adaptive variation is particularly important for TGF because this conservation strategy is based on the redistribution of adaptive variation and the subsequent evolutionary response. For TGF we need to identify where our best sources of adaptive diversity are, and we need to move individuals from these source populations to recipient populations. Where should we be looking for our best sources of adaptive diversity? Here, we draw on both ecological and evolutionary theory to argue that, in many systems, the obvious place to look for adaptive variation is in peripheral isolates: genetically isolated, yet persistent, populations on the margin of the species' existing range.

The ranges of many species are made up of large, central populations surrounded by numerous, smaller peripheral populations. These small, relatively isolated populations have long been recognized as an important source of adaptive diversity (e.g., Bush, 1975). Indeed, it has been more than 20 years since Lesica and Allendorf (1995) first highlighted the conservation value of the adaptive diversity held in such populations. Although evidence for the value of marginal populations exists (e.g., Hampe and Petit, 2005), there has been little work done to clarify which marginal populations are likely to be most important, and why. In addition, our goalposts have shifted: from looking at peripheral isolates as places evolutionary novelty might occur, to looking at them as potential sources for TGF or assisted colonization. For these applications we are looking for populations that are adapted to the future climate elsewhere in the species range. Fortunately, both ecological and evolutionary theory show remarkable agreement regarding the habitat and population characteristics that determine a population's likely degree of adaptive divergence for climate-relevant traits. Both perspectives identify population size, connectivity, and climatic environment as key factors. Evolutionary considerations also point to the importance of long-term persistence in isolation. Although ecological and evolutionary perspectives agree on these fundamental axes of importance, there is less agreement about optimal positioning along each axis, and new empirical data will be critical in addressing this uncertainty.

To illustrate our ideas, we use the rainforests of Australia's Wet Tropics as a model system. The Australian Wet Tropics bioregion is in the north-east of the continent (Figure $\mathbf{1}$ inset), and consists of a complex network of rainforest patches (naturally occurring fragments of rainforest habitat shaped by past climate change, and continuing to be shaped by anthropogenic disturbance) in a matrix of monsoonal woodlands. The highly endemic rainforest biota has been highlighted as being sensitive to both past (Graham et al., 2006) and future (Williams et al., 2003) climate change. For rainforest-restricted species, rainforest patches represent potential habitat that can be scored for their size, connectivity, and climate. Where it is necessary to think about the landscape from the perspective of a particular species, we have chosen a small rainforest skink (Lampropholis coggeri) primarily because its dispersal rate has been estimated and is low. Results generated for this species should be broadly indicative of results for many other low vagility rainforest taxa.

\section{THE EVOLUTIONARY ECOLOGY OF ISOLATION}

\section{The Geometry of Isolation}

Our argument for the likely importance of peripheral isolation flows from the geometric fact that peripheral isolates occupy habitat patches at the periphery of the species' range. As such they are likely (a) numerous, and (b) spread across a broad range of climatic conditions. In Australia's Wet Tropics rainforests, 


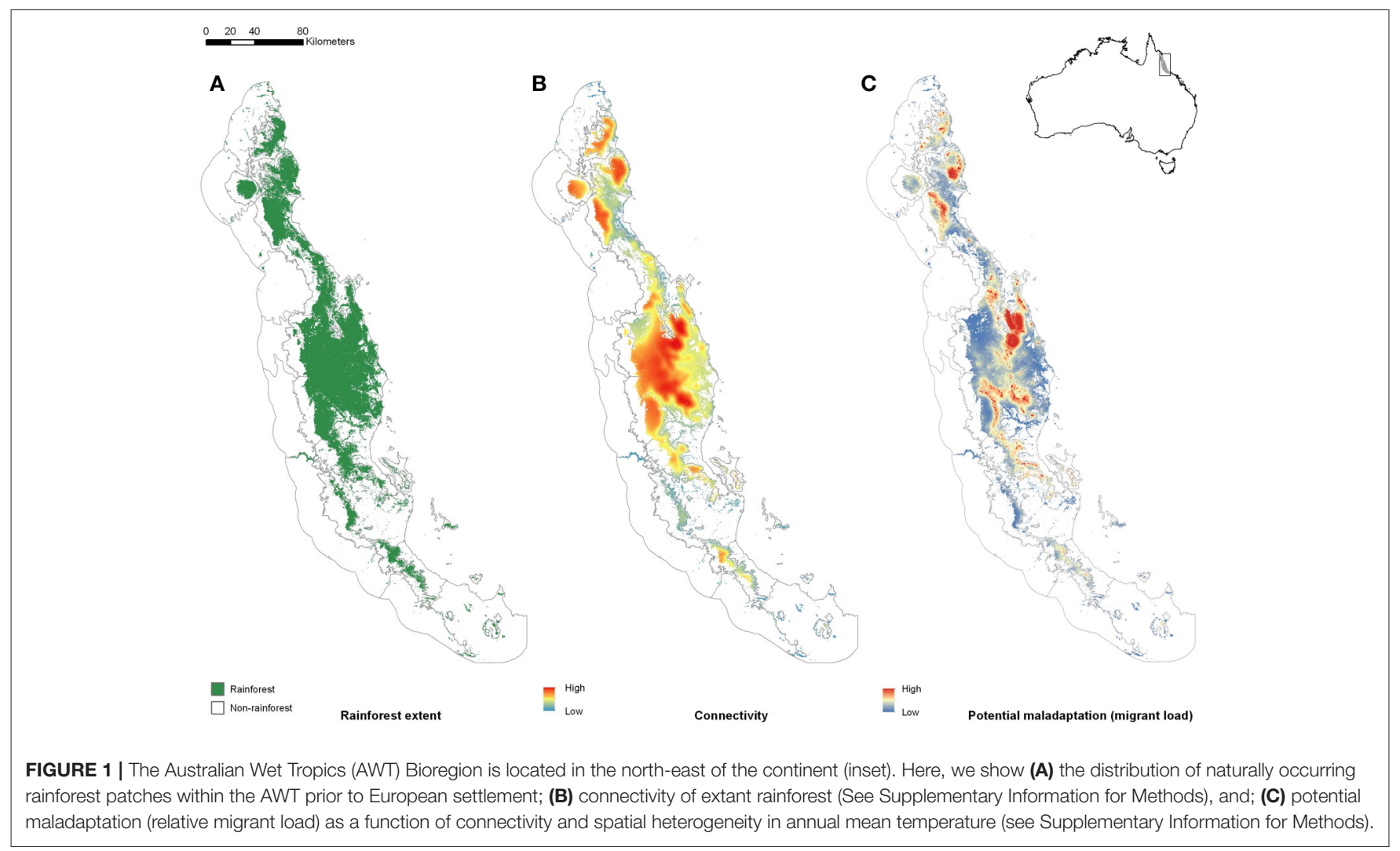

for example, we see a central spine of core habitat, surrounded by numerous $(>7,000)$ naturally isolated patches of rainforest (the pre-clearing distribution of rainforest: Figure 1A). Here, we have defined "core" patches as the largest patch of rainforest in each of 21 major faunal subregions within the Wet Tropics bioregion (Williams and Pearson, 1997), with all other patches being peripheral to these. Although the peripheral patches represent approximately $10 \%$ of the area of rainforest habitat in the region, they encompass almost all of the regional climatic variation (Figure 2). The only climate spaces not sampled in peripheral patches are the most extreme wet and cool areas, found at the top of the mountain ranges around which the core areas are located. Conversely, the peripheral patches contain climate spaces (particularly the warmer, drier climates) that are not represented in the core patches (Figure 2). While it is convenient to think of habitat patches as being either core or peripheral, connectivity is in reality a continuous variable, with patch connectivity ranging from low (peripheral) to high (core). For convenience, we continue to refer to our patches as either core or peripheral; however, all our analyses have been performed with a continuous connectivity index (see Figure 1B, and Supplementary Material for Methods). Given that these peripheral patches sample most of the climate space of the region, especially at the warm-dry end of the spectrum, the next question is whether populations inside these patches (our "peripheral isolates") show adaptations matching their particular part of climate space; is this sampling of climate space reflected in the species trait space?
Consideration of evolutionary theory would suggest that, by dint of their isolation, populations in peripheral isolates should adapt more closely to their environment than core populations. The degree to which a population can adapt to its environment depends not only upon the rate of environmental change, but also on how much maladaptive gene flow a population receives (Polechová et al., 2009). Assuming that phenotypes are constantly evolving to match the local environment, this "migrant load", $M$, scales directly with the product of the number of migrants, $m$, and the environmental difference between source and recipient population, $b$ (Kirkpatrick and Barton, 1997; Polechová et al., 2009). Populations receiving many immigrants from climatically divergent areas are less likely to be closely adapted to local conditions than are populations that do not receive these migrants, or that only receive migrants from climatically similar environments.

We can map an index of relative migrant load in our system by multiplying a measure of habitat connectivity $(\approx m)$ with a measure of environmental heterogeneity $(\approx b)$. The measure of connectivity is a spatially-weighted average of habitat quality around a location. As such it is a rough index of the relative number of migrants to a location (locations surrounded by high quality habitat will have greater number of migrants than locations surrounded by poor quality habitat; see Supplementary Material for Methods). The measure of heterogeneity is a spatially-weighted standard deviation of environmental conditions around a location. In both cases the spatial-weighting is specific to the dispersal capabilities of the 
Core vs peripheral climates

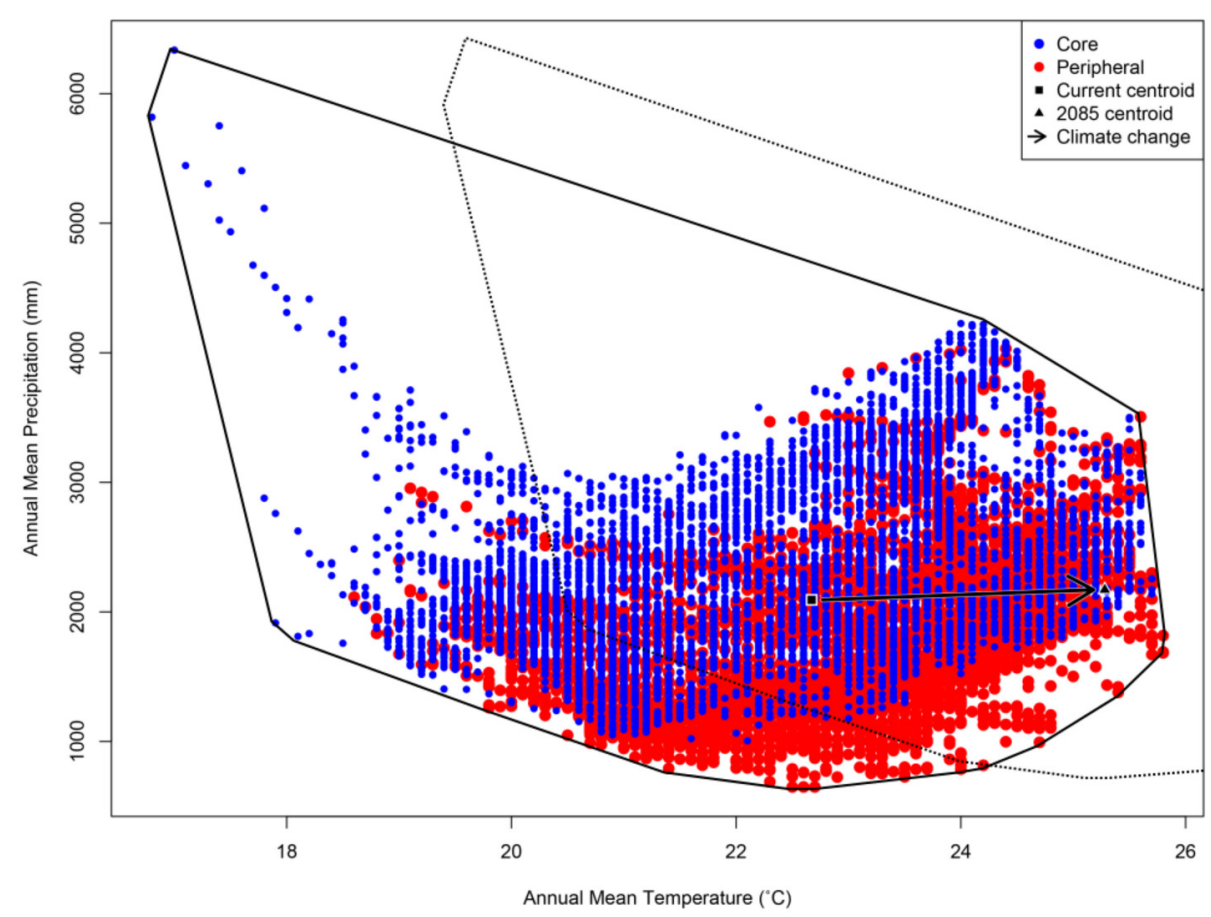

FIGURE 2 | Scatterplot showing spatial variation in two important axes of climate (annual mean temperature and annual mean precipitation) in Australia's Wet Tropics (AWT). The vector shows the expected shift in the centroid of this climate envelope under climate change. Variation is shown for random points in each of 7,095 peripheral AWT rainforest patches (red); and, 7,095 random points in core AWT rainforest patches (blue). In the AWT, the only climate space not represented by peripheral patches is in the extreme wet-and-cool corner surrounding core patches (i.e., mountain tops in the AWT). Conversely, peripheral patches contain some climate spaces (particularly the warmer, drier climates) that are not represented in core patches. Polygons indicate the current climate envelope (solid line) and the future envelope (dashed line) produced by shifting the centroid.

species or group in question. Combining these two indices in our case reveals clear variation through space in our index of migrant load (Figure 1). It is clear that peripheral patches in our example tend to have far lower migrant loads than core patches (Figure 1). Thus, peripheral patches sample the climate space well, and likely suffer less from the influence of maladaptive gene flow. Together, these results suggest that peripheral patches may provide a useful source of climate-associated adaptive variation.

But how do we choose between peripheral patches? Which patches will be most suitable as a source of adaptive diversity? This is a complex question and we do not answer it completely here. Instead, we point to three axes of variation that constitute a useful prism through which to view the problem. Ecological and evolutionary perspectives suggest the adaptive trajectory of the population with respect to climate will largely be determined by: population size, population connectivity, and climatic environment. We touch briefly on each of these axes of variation in turn.

\section{Population Size}

Peripheral patches and the populations they contain are, by definition, smaller than their core counterparts. If population size scales with patch size, then peripheral isolates have smaller population sizes than is found in core areas. In our Wet Tropics example, peripheral patches are, on average, a mere $0.47 \%$ of the size of core patches. Their small area is one of the characteristics that make them interesting, as it allows many of them to be scattered across a broad sample of environmental space, but the size of isolates also will determine the likelihood of population persistence and local adaptation.

From an ecological perspective, patch size (and, by extrapolation, population size) is seen as a critical determinant of population persistence; small populations are more prone to extinction through demographic and environmental stochasticity (Lande, 1993). From an evolutionary perspective, population size also determines the balance between genetic drift and selection. In sufficiently small populations, drift can overwhelm selection and even deleterious mutations can drift to fixation (Kimura, 1979). Because of this, we might expect smaller populations to be less locally adapted, due to the stronger effects of drift (Weiss and Goodman, 1972; Petren et al., 2005; Lopez et al., 2009). And there is empirical evidence that this occurs (Hereford, 2009). In a review of local adaptation in plants, for example, Leimu and Fischer (2008) found that populations with fewer than 1,000 flowering individuals showed weaker local adaptation compared with larger populations. Thus, as populations become small they may diverge substantially from the parental population, but for reasons having nothing to do with adaptation. Both evolutionary 
and ecological theory agree that, to persist as a viable locally adapted population, patches need to be large enough to support populations that are buffered from the worst excesses of genetic drift and demographic stochasticity.

How do we tell if a population is large enough? A simple metric here is long-term persistence. Populations that are too small will have a strong tendency to go extinct through inbreeding, drift, and demographic stochasticity. We are not talking here about sink populations that persist only because they are constantly bolstered by immigration (see next section); rather, we are talking about populations that persist largely on their own merit. Such persistent isolates will be locally adapted either because of selection in situ or because, through selective extinction of less resilient populations, the only populations still present are those resilient to living in isolates (Balmford, 1996); a kind of group selection. One way, therefore, to measure the likelihood of local adaptation in a patch is to consider the historical demography in that patch; populations that show genetic signatures of long-term isolation and demographic stability (e.g., Leblois et al., 2014) likely are composed of individuals well-adapted to local conditions.

It is clear then that the most interesting source populations for TGF are those that are small, but not too small. Or to put it another way, populations that are small but which, nonetheless, show evidence of persistence despite long-term isolation.

\section{Population Connectivity}

As well as its size, an isolate's physical proximity to other isolates will greatly influence its immigration rate. This, in turn, has implications for population size and stability, with well-connected patches typically having more persistent, stable populations (Levin et al., 1984). Thus, ecological theory generally sees high connectivity as beneficial because of its stabilizing influence on demography. Evolutionary theory, however, takes a more dichotomous view. On one hand connectivity increases gene flow, which, even at low levels, increases genetic variance and evolutionary potential (Polechová et al., 2009). On the other hand, high connectivity increases migrant load, and when maladaptive gene flow is high enough it can, in theory, overwhelm or swamp local adaptation, either transiently or permanently (Haldane, 1956; Kirkpatrick and Barton, 1997; Lenormand, 2002; Débarre et al., 2013). Not only is the level of gene flow critical, but so too is its source. Sexton et al. (2011), for example, found that cross-pollination of a plant between warmedge peripheral populations increased fitness, whereas crosspollination between a peripheral and a core population decreased fitness.

This concept of migrant load swamping the effect of natural selection is the reason that isolation is considered so important for adaptation (García-Ramos and Kirkpatrick, 1997). If an isolated population has sufficient genetic variation, it will adapt to its local conditions, and this adaptation can occur rapidly. For example, the work of Losos et al. (1997) on experimentally isolated Caribbean Anolis lizards showed that morphological divergence driven by differences in habitat appeared within 10-14 years. In the face of strong gene flow from environmentally distinct populations, however, theory suggests that adaptation to local conditions will likely take substantially longer, if it occurs at all (Holt and Gomulkiewicz, 1997; Bridle et al., 2009; Polechová et al., 2009; Phillips, 2012).

Therefore, because they receive some influx of genetic diversity but not enough to swamp local adaptation, populations that are weakly connected and long-term persistent should be very well-adapted to local conditions. Choosing populations that do not experience strong gene flow also ensures that we avoid ecological-sink populations; those maintained purely by immigration.

So again, there is a "sweet spot"- this time between no gene flow, and too much gene flow-around which our best candidate populations will rest.

An additional consideration here is that evidence of some gene flow suggests that a population has not developed coadapted gene complexes that work against successful admixture by reducing fitness of admixed individuals: "outbreeding depression". For TGF to be successful, the genes from translocated individuals need to introgress into the recipient population, and this may be less successful when a population has been reproductively isolated for very long periods of time (Coyne and Orr, 1998; Singhal and Moritz, 2013). These genetic barriers to introgression have likely been greatly overstated (Weeks et al., 2011) and are only likely to be relevant where there are very long divergence times in which incompatibilities have developed across large sections of the genome. Without this extensive distribution of incompatibilities, we would expect advantageous (but not disadvantageous) alleles to introgress into the recipient population relatively unimpeded (Barton, 1979; Aitken and Whitlock, 2013). In summary, evolutionary theory, in contrast to ecological theory, suggests that low connectivity is optimal for isolates that may act as a source for TGF.

Although connectivity is not necessarily easy to measureit can vary over time, as well as space-there are numerous simple proxy measures of connectivity, using geospatial data, that perform adequately against genetic metrics (e.g., Palmer et al., 2011). Using modeled habitat suitability in the Wet Tropics, and integrating these suitabilities over space (using speciesspecific dispersal expectations, see Supplementary Material), we generated both point- and patch-level indices of connectivity for the Wet Tropics. When we score connectivity in this way we get the unsurprising result that connectivity declines toward the edges of large habitat blocks, and is generally much lower in isolated patches than in larger habitat blocks (Figure 1B). Of course, genetic data on immigration rates between patches would be useful to ground-truth such landscape connectivity measures, but they are not strictly necessary: in the absence of genetic data, useful measures of relative connectivity can be derived from readily available GIS data.

While low connectivity facilitates evolution, it is not a driver of adaptation; it simply provides ideal conditions under which populations can respond to selection pressures without undue migrant load (Dawson and Hamner, 2005). Those selection pressures come from the environment, which brings us to our third important axis: the climatic environment. 


\section{Climatic Environment}

Geographic variation in climate is ubiquitous. Factors such as latitude, vegetation cover, elevation, and distance from the coastline all create substantial spatial variation in climate (e.g., Shoo et al., 2010, 2011). Indeed, microclimate may differ over even very small landscape scales (e.g., Pinto et al., 2010). For all of these reasons, isolates at the geographic edge of a species' range will likely experience a different climate (both in mean and extreme values) from the climate at the center of the species' range (Lesica and Allendorf, 1995). In other words, geographic marginality may often correlate with ecological marginality, particularly for climate. In the Wet Tropics, for example, it is clear that weakly connected patches also tend to have marginal climates (Figure 3).

One of our rationales for focusing on peripheral isolates as a source of adaptive diversity is precisely because they likely sample these extreme climates and, subject to persistence, are more than likely adapted to the climatic conditions in their habitat patch. Given the current trajectory of climate change (we are tracking toward a $>4^{\circ} \mathrm{C}$ increase in mean global temperature by 2,100 ; Meehl et al., 2007), it is inevitable that source populations of interest to managers for TGF will tend to be at the extremes of the available climate space. Insofar as species distributional limits are associated with climate (and they often are: Kearney and Porter, 2004; Gaston, 2009), these extremes of climate space will tend to be found in isolates, at the extremes of geographic space. If we examine patches that are too far into extreme climate spaces, however, it is unlikely that the species will be present. If we do not go far enough, it is likely that we will ineffectively sample the adaptive diversity contained within the species' range. Thus, we are searching for populations that exist on the borderline (in climate space) between extinction and persistence through adaptation.

If we examine this edge (in climate space) between population persistence and extinction, we not only survey the locations containing important adaptive diversity, but we also learn about the limits of adaptation to climate. Because these peripheral isolates are naturally occurring and have often been in existence for at least several thousand years (many could be early Holocene relicts, sensu; Hampe and Jump, 2011), they provide a good snapshot of the adaptive capacity of a species (e.g., Llewelyn et al., 2016). If, based on size and connectivity, a species should be present in a patch but is not, then there might be a case that the environment in that location is too extreme, and beyond the limits of that species' capacity to adapt.

Given the breadth of environmental sampling by peripheral patches, it is likely that a subset of isolates is currently in climate space beyond that occupied by core populations. This appears true in the Wet Tropics, where warmer, drier climates are better represented in peripheral patches than in the core patches (Figure 2). Some of these isolates are already in a climate space that will manifest in core populations under climate change; such isolates could provide the adaptive variation needed by core populations to evolutionarily respond to the changing conditions. If, however, the additional climate space captured by peripheral isolates falls counter to the direction of climate change (as it might in a system other than the Wet Tropics), the utility of
TGF may be badly undermined and more intensive actions (e.g., assisted colonization) may be required.

Importantly, peripheral patches will not only tend to differ in mean climate variables (e.g., annual mean temperature and precipitation), but will also likely differ in the variation around those climatic means (Figure 3). As alluded to above (section: Size), isolates, by virtue of their small size and geographic marginality, likely experience more extreme events than populations in the core of a species' range. Thus, plasticity in individual behavior and physiology that increases survival during these extreme events should be favored by recurrent selection in isolates (Hoffmann and Parsons, 1991; Hoffmann and Sgrò, 2011; Phillips et al., 2015): isolates that have experienced regular extreme events in the past could be better adapted to deal with extreme events in the future.

\section{THE CONSERVATION SIGNIFICANCE OF PERIPHERAL ISOLATES IN A CHANGING WORLD}

For any given threatening process, appropriate adaptive variation may be more prevalent in peripheral isolates than anywhere else. Evidence for this proposition comes from recent observations of "extinct" species being rediscovered on the very margins of their former ranges. Fisher (2011), for example, found that mammals presumed to be extinct were more likely to be rediscovered at the periphery of their former range, rather than the center, and a similar pattern may be emerging from recent frog "extinctions" (e.g., Puschendorf et al., 2011). Additionally, in a meta-analysis of 134 studies of neutral genetic diversity, Eckert et al. (2008) found that most studies (70.2\%) reported increased betweenpopulation divergence amongst peripheral isolates. Whether this broad survey of neutral diversity reflects patterns in phenotypic diversity, however, still remains to be seen (Eckert et al., 2008).

As well as representing perhaps the bulk of adaptive diversity in a species, peripheral isolates may provide evidence of what species are capable of adapting to and may also provide the raw genetic material that will enable species to adapt and/or shift in response to uncertain climatic change in the future (Budd and Pandolfi, 2010). Of course, we are not advocating the preservation of all peripheral isolates at the expense of core populations; rather, our point is that it is important to assess the diversity within them and potentially harness this diversity, before it is lost to climate change. Despite the fact that peripheral habitats may contain populations that are pre-adapted to the future climate of core areas, they may still be some of the first populations to go extinct as climate change progresses. This counter-intuitive outcome occurs because, as conditions in the core areas of the species' range approach the extreme conditions found in an isolate, the conditions in the isolate become yet more extreme. This, coupled with their small size and isolation from other populations, means that peripheral isolates (and particularly the ones we are interested in: hot-adapted and rear-edge isolates) may well be some of the first local populations to be extirpated by climate change. Thus, if we are to understand and harness the adaptive diversity expected in peripheral isolates, we must do so as a matter of urgency (Hampe and Petit, 2005). 

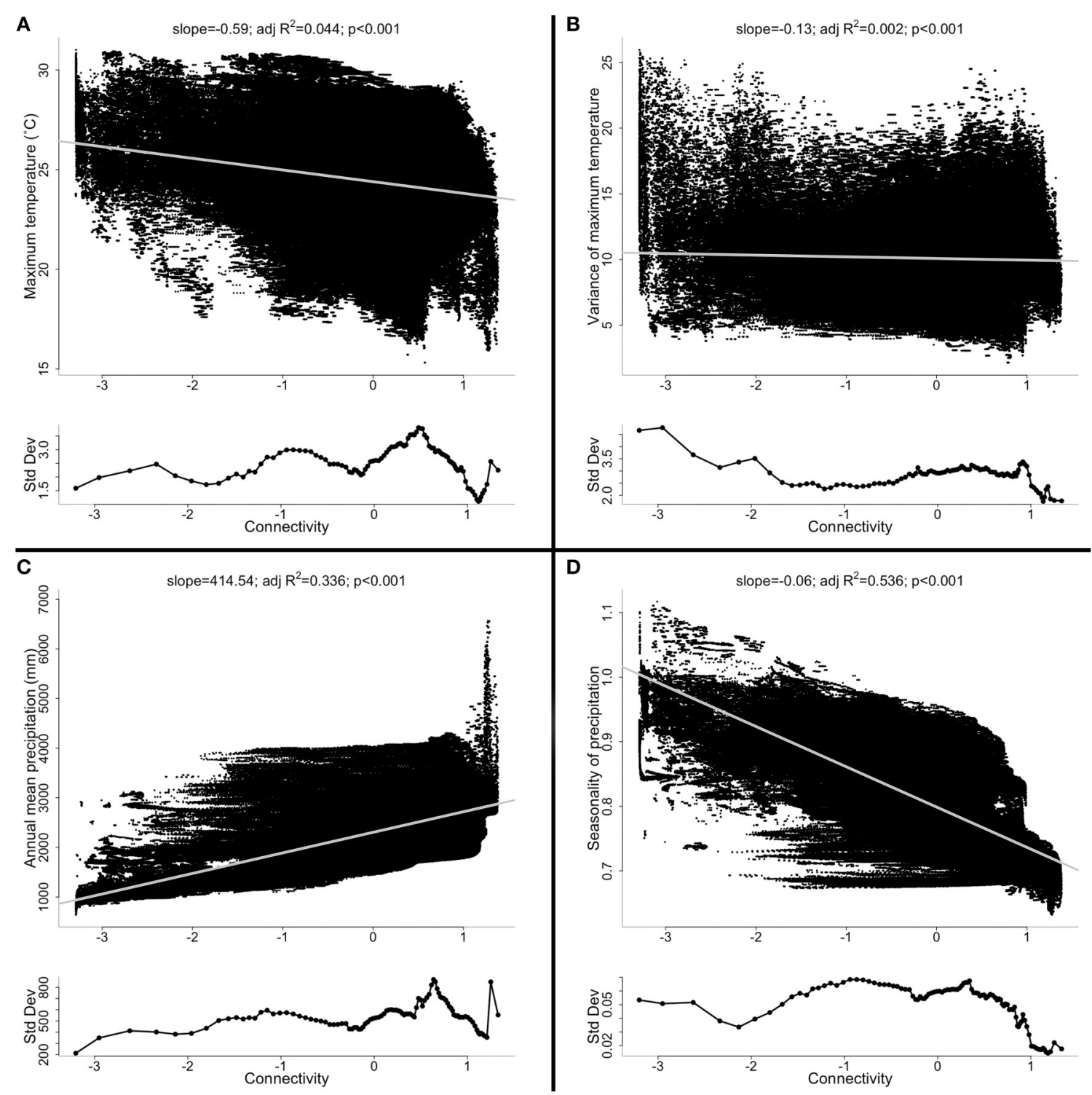

FIGURE 3 | The relationship between connectivity and (A) average maximum daily temperature (Tmax); (B) variance of Tmax; (C) annual mean precipitation; and (D) seasonality of precipitation. Also shown is the relationship between connectivity and the standard deviation of each of the above climatic variables (lower inset panels) In Australia's Wet Tropics, geographic marginality (defined here by connectivity) is often related systematically to climate. Weakly and strongly connected populations often differ in mean climate. The variation in climate sampled, however, (lower inset panels) is often just as high, or higher, in the weakly connected populations as it is in the strongly connected populations. See Supplementary Information for more details.

We identified three axes of variation that can be used to characterize patches: size, connectivity and climatic environment. These three patch characteristics can, in principle, be used to predict the current locations at which climate-relevant diversity occurs. Unfortunately, our recommendations with regard to where along each of these axes we would expect to see the highest diversity are vague, and will continue to be so until empirical data on local adaptation have been collected. Candidate isolates should be small, but not so small that drift overwhelms selection. Candidate isolates should experience low levels of gene flow: less than in a contiguous population (to avoid swamping effects, and to ensure that the population is not a sink and not reproductively isolated), but enough gene flow to prevent excessive erosion of genetic diversity through drift, inbreeding, and selection. Finally, isolates should come from extreme climatic environments: at the climatic edges of what the species is capable of. Although vague, many of these constraints can be satisfied by the very fact of a population's persistence. If a small isolate is persisting in a peripheral climate, and there is evidence that it has done so for a considerable period of time, then it has likely adapted to its local conditions. If it had failed to adapt, it simply would not be there. 
To inform conservation actions for a given species and system, these recommendations should be backed up with relevant data. Importantly, readily available spatial and climate data allow us to identify patches and examine their distribution along each of these three axes; we have illustrated this possibility with our case study. Determining where those peripheral isolates with the most value as sources of adaptive diversity are-populations that have persisted and adapted through time-requires further data. A useful sampling regime would examine presence/absence and phenotypic and molecular diversity in a representative sample of patches as a means of identifying how our three axes relate to adaptive divergence. Collecting these data is not a small task, but it is a necessary one if we are to locate populations containing important adaptive variation and harness this variation for management.

\section{CONCLUSION}

Because isolated populations as a set may represent the bulk of within-species phenotypic diversity, these isolated populations are where we should look for the genetic variation necessary to bolster populations threatened by climate change. The very characteristics that make these isolates important-their small size, isolation, and marginal climate-also mean they may be some of the first populations to go extinct under anthropogenic climate change. Given the rapid rate of climate change, a focus on the adaptive diversity present in isolates, particularly those at the rear edge of climate-shifting populations, should be a matter of urgency. Above, we outline important patch traits (i.e., size, connectivity, and climatic extremity) that will assist in identifying high quality source populations for TGF. Although these patch trait axes are important, we remain vague about precisely where in this trait space ideal source populations will be found. This vagueness can be resolved empirically, however. In an ideal world, we would (1) collect presence/absence data and perform

\section{REFERENCES}

Aitken, S. N., and Whitlock, M. C. (2013). Assisted gene flow to facilitate local adaptation to climate change. Annu. Rev. Ecol. Evol. Syst. 44, 367-388. doi: 10.1146/annurev-ecolsys-110512-135747

Atkins, K. E., and Travis, J. M. J. (2010). Local adaptation and the evolution of species' ranges under climate change. J. Theor. Biol. 266, 449-457. doi: 10.1016/j.jtbi.2010.07.014

Balmford, A. (1996). Extinction filters and current resilience: the significance of past selection pressures for conservation biology. Trends Ecol. Evol. 11, 193-196. doi: 10.1016/0169-5347(96)10026-4

Barton, N. (1979). Gene flow past a cline. Heredity 43, 333-339. doi: 10.1038/hdy.1979.86

Bridle, J. R., Gavaz, S., and Kennington, W. J. (2009). Testing limits to adaptation along altitudinal gradients in rainforest Drosophila. Proc. R. Soc. Biol. Sci. 276, 1507-1515. doi: $10.1098 / \mathrm{rspb} .2008 .1601$

Budd, A. F., and Pandolfi, J. M. (2010). Evolutionary novelty is concentrated at the edge of coral species distributions. Science 328, 1558-1561. doi: $10.1126 /$ science.1188947

Bush, G. L. (1975). Modes of animal speciation. Annu. Rev. Ecol. Syst. 6, 339-364. doi: 10.1146/annurev.es.06.110175.002011

Coyne, J. A., and Orr, H. A. (1998). The evolutionary genetics of speciation. Philos. Trans. R. Soc. Lond. B Biol. Sci. 353, 287-305. doi: 10.1098/rstb.1998.0210 patch occupancy modeling (what are the climate extremes for persistence of the species?); (2) use genetic tools to assess gene flow across the landscape, and to assess population demographic history (which populations at climatic extremes show long-term persistence and low levels of gene flow?); (3) assess how species trait variation (e.g., in climate-relevant physiological traits) is distributed across the landscape and how this relates to climatic variation (which climate axes are most important for fitness?). We note, however, that we do not live in an ideal world. We may be running out of time for such ideal background information, in which case our three-axis framework acts as a useful heuristic for guiding management.

\section{AUTHOR CONTRIBUTIONS}

SM collated data sources; SM and BP conceived and performed analyses; SM wrote manuscript; BP, JL, and CM edited manuscript; all authors contributed substantially to ideas and revisions.

\section{ACKNOWLEDGMENTS}

Jeremy VanDerWal provided useful advice on the manipulation and analysis of spatial datasets used here. We thank the Australian Research Council for funding this work (DP1094646, FL110100104, DP130100318, FT160100198); the Tropical Landscapes Joint Venture (a collaboration between CSIRO and JCU) for support to SM and JL; and the Wet Tropics Management Authority for support to SM.

\section{SUPPLEMENTARY MATERIAL}

The Supplementary Material for this article can be found online at: http://journal.frontiersin.org/article/10.3389/fevo. 2017.00088/full\#supplementary-material

Dawson, M. N., and Hamner, W. M. (2005). Rapid evolutionary radiation of marine zooplankton in peripheral environments. Proc. Natl. Acad. Sci. U.S.A. 102, 9235-9240. doi: 10.1073/pnas.05036 35102

Débarre, F., Ronce, O., and Gandon, S. (2013). Quantifying the effects of migration and mutation on adaptation and demography in spatially heterogeneous environments. J. Evol. Biol. 26, 1185-1202. doi: 10.1111/jeb. 12132

Eckert, C., Samis, K., and Lougheed, S. (2008). Genetic variation across species' geographical ranges: the central-marginal hypothesis and beyond. Mol. Ecol. 17, 1170-1188. doi: 10.1111/j.1365-294X.2007.03659.x

Fisher, D. O. (2011). Trajectories from extinction: where are missing mammals rediscovered? Glob. Ecol. Biogeogr. 20, 415-425. doi: 10.1111/j.1466-8238.2010.00624.x

Flannery, T. (2006). The Weather Makers: How Man is Changing the Climate and What it Means for Life on Earth. Melbourne, VIC: Text Publishing.

Freeman, B. G., and Freeman, A. M. C. (2014). Rapid upslope shifts in New Guinean birds illustrate strong distributional responses of tropical montane species to global warming. Proc. Natl. Acad. Sci. U.S.A. 111, 4490-4494. doi: $10.1073 /$ pnas.1318190111

García-Ramos, G., and Kirkpatrick, M. (1997). Genetic models of adaptation and gene flow in peripheral populations. Evolution 51, 21-28. doi: 10.1111/j.1558-5646.1997.tb02384.x 
Gaston, K. J. (2009). Geographic range limits: achieving synthesis. Proc. R. Soc. Biol. Sci. 276, 1395-1406. doi: 10.1098/rspb.2008.1480

Graham, C. H., Moritz, C., and Williams, S. E. (2006). Habitat history improves prediction of biodiversity in rainforest fauna. Proc. Natl. Acad. Sci. U.S.A. 103, 632-636. doi: 10.1073/pnas.0505754103

Haldane, J. (1956). The relation between density regulation and natural selection. Proc. R. Soc. Biol. Sci. 145, 306-308. doi: 10.1098/rspb.1956.0039

Hampe, A., and Jump, A. S. (2011). Climate relicts: past, present, future. Annu. Rev. Ecol. Evol. Syst. 42, 313-333. doi: 10.1146/annurev-ecolsys-102710-145015

Hampe, A., and Petit, R. J. (2005). Conserving biodiversity under climate change: the rear edge matters. Ecol. Lett. 8, 461-467. doi: $10.1111 /$ j.1461-0248.2005.00739.x

Hereford, J. (2009). A quantitative survey of local adaptation and fitness trade-offs. Am. Nat. 173, 579-588. doi: 10.1086/597611

Hoegh-Guldberg, O., Hughes, L., McIntyre, S., Lindenmayer, D. B., Parmesan, C., Possingham, H. P., et al. (2008). Assisted colonization and rapid climate change. Science 321, 345-346. doi: 10.1126/science.1157897

Hoffmann, A. A., and Parsons, P. A. (1991). Evolutionary Genetics and Environmental Stress. New York, NY: Oxford University Press.

Hoffmann, A. A., and Sgrò, C. M. (2011). Climate change and evolutionary adaptation. Nature 470, 479-485. doi: 10.1038/nature09670

Holt, R. D., and Gomulkiewicz, R. (1997). How does immigration influence local adaptation? A reexamination of a familiar paradigm. Am. Nat. 149, 563-572. doi: $10.1086 / 286005$

Jones, P. D., New, M., Parker, D. E., Martin, S., and Rigor, I. G. (1999). Surface air temperature and its changes over the past 150 years. Rev. Geophys. 37, 173-199. doi: 10.1029/1999RG900002

Kearney, M., and Porter, W. P. (2004). Mapping the fundamental niche: physiology, climate, and the distribution of a nocturnal lizard. Ecology 85, 3119-3131. doi: 10.1890/03-0820

Kelly, E. L., and Phillips, B. L. (2016). Targeted gene flow for conservation. Conserv. Biol. 30, 259-267. doi: 10.1111/cobi.12623

Kimura, M. (1979). Model of effectively neutral mutations in which selective constraint is incorporated. Proc. Natl. Acad. Sci. U.S.A. 76, 3440-3444. doi: $10.1073 /$ pnas.76.7.3440

Kirkpatrick, M., and Barton, N. H. (1997). Evolution of a species' range. Am. Nat. 150, 1-23. doi: 10.1086/286054

Lande, R. (1993). Risks of population extinction from demographic and environmental stochasticity and random catastrophes. Am. Nat. 142, 911-927. doi: $10.1086 / 285580$

La Sorte, F. A., and Jetz, W. (2010). Projected range contractions of montane biodiversity under global warming. Proc. R. Soc. Biol. Sci. 277, 3401-3410. doi: 10.1098/rspb.2010.0612

Lavergne, S., Mouquet, N., Thuiller, W., and Ronce, O. (2010). Biodiversity and climate change: integrating evolutionary and ecological responses of species and communities. Annu. Rev. Ecol. Evol. Syst. 41, 321-350. doi: 10.1146/annurev-ecolsys-102209-144628

Leblois, R., Pudlo, P., Néron, J., Bertaux, F., Beeravolu, C. R., Vitalis, R., et al. (2014). Maximum-likelihood inference of population size contractions from microsatellite data. Mol. Biol. Evol. 31, 2805-2823. doi: $10.1093 / \mathrm{molbev} / \mathrm{msu} 212$

Leimu, R., and Fischer, M. (2008). A meta-analysis of local adaptation in plants. PLoS ONE 3:e4010. doi: 10.1371/journal.pone.0004010

Lenormand, T. (2002). Gene flow and the limits to natural selection. Trends Ecol. Evol. 17, 183-189. doi: 10.1016/S0169-5347(02)02497-7

Lesica, P., and Allendorf, F. W. (1995). When are peripheral populations valuable for conservation? Conserv. Biol. 9, 753-760. doi: 10.1046/j.1523-1739.1995.09040753.x

Levin, S. A., Cohen, D., and Hastings, A. (1984). Dispersal strategies in patchy environments. Theor. Popul. Biol. 26, 165-191. doi: 10.1016/0040-5809(84)90028-5

Llewelyn, J., Macdonald, S., Hatcher, A., Moritz, C., and Phillips, B. L. (2016). Intraspecific variation in climate-relevant traits in a tropical rainforest skink. Divers. Distrib. 22, 1000-1012. doi: 10.1111/ddi. 12466

Loarie, S. R., Duffy, P. B., Hamilton, H., Asner, G. P., Field, C. B., and Ackerly, D. D. (2009). The velocity of climate change. Nature 462, 1052-1055. doi: $10.1038 /$ nature08649
Lopez, S., Rousset, F., Shaw, F. H., Shaw, R. G., and Ronce, O. (2009). Joint effects of inbreeding and local adaptation on the evolution of genetic load after fragmentation. Conserv. Biol. 23, 1618-1627. doi: 10.1111/j.1523-1739.2009.01326.x

Losos, J. B., Warheit, K. I., and Schoener, T. W. (1997). Adaptive differentiation following experimental island colonization in Anolis lizards. Nature 387, 70-73. doi: $10.1038 / 387070 \mathrm{a} 0$

Marris, E. (2009). Forestry: planting the forest of the future. Nature 459, 906-908. doi: $10.1038 / 459906 a$

McLachlan, J. S., Hellmann, J. J., and Schwartz, M. W. (2007). A framework for debate of assisted migration in an era of climate change. Conserv. Biol. 21, 297-302. doi: 10.1111/j.1523-1739.2007.00676.x

Meehl, G. A., Stocker, T. F., Collins, W. D., Friedlingstein, P., Gaye, A. T., Gregory, J. M., et al. (2007). "Global climate projections," in Climate Change 2007:The Physical Science Basis. Contribution of Working Group I to the Fourth Assessment Report of the Intergovernmental Panel on Climate Change, eds S. Solomon, D. Qin, M. Manning, Z. Chen, M. Marquis, K. B. Averyt, M. Tignor, and H. L. Miller (Cambridge, UK; New York, NY: Cambridge University Press), 747-845.

Miller, K. A., Miller, H. C., Moore, J. A., Mitchell, N. J., Cree, A., Allendorf, F. W., et al. (2012). Securing the demographic and genetic future of Tuatara through assisted colonization. Conserv. Biol. 26, 790-798. doi: 10.1111/j.1523-1739.2012.01902.x

Moritz, C., and Agudo, R. (2013). The future of species under climate change: resilience or decline? Science 341, 504-508. doi: 10.1126/science.1237190

Norberg, J., Urban, M. C., Vellend, M., Klausmeier, C. A., and Loeuille, N. (2012). Eco-evolutionary responses of biodiversity to climate change. Nat. Clim. Chang. 2, 747-751. doi: 10.1038/nclimate1588

Palmer, S. C. F., Coulon, A., and Travis, J. M. J. (2011). Introducing a 'stochastic movement simulator' for estimating habitat connectivity. Methods Ecol. Evol. 2, 258-268. doi: 10.1111/j.2041-210X.2010.00073.x

Parmesan, C. (2006). Ecological and evolutionary responses to recent climate change. Annu. Rev. Ecol. Evol. Syst. 37, 637-669. doi: 10.1146/annurev.ecolsys.37.091305.110100

Petren, K., Grant, P., Grant, B., and Keller, L. (2005). Comparative landscape genetics and the adaptive radiation of Darwin's finches: the role of peripheral isolation. Mol. Ecol. 14, 2943-2957. doi: 10.1111/j.1365-294X.2005. 02632.x

Phillips, B. L. (2012). Range shift promotes the formation of stable range edges. J. Biogeogr. 39, 153-161. doi: 10.1111/j.1365-2699.2011.02597.x

Phillips, B. L., Muñoz, M. M., Hatcher, A., Macdonald, S. L., Llewelyn, J., Lucy, V., et al. (2015). Heat hardening in a tropical lizard: geographic variation explained by the predictability and variance in environmental temperatures. Funct. Ecol. 30, 1161-1168. doi: 10.1111/1365-2435.12609

Pinto, S. R. R., Mendes, G., Santos, A. M. M., Dantas, M., Tabarelli, M., and Melo, F. P. L. (2010). Landscape attributes drive complex spatial microclimate configuration of Brazilian Atlantic forest fragments. Trop. Conserv. Sci. 3, 389-402. doi: 10.1177/194008291000300404

Polechová, J., Barton, N., and Marion, G. (2009). Species' range: adaptation in space and time. Am. Nat. 174, E186-E204. doi: 10.1086/605958

Puschendorf, R., Hoskin, C. J., Cashins, S. D., McDonald, K., Skerratt, L. F., Vanderwal, J., et al. (2011). Environmental refuge from disease-driven amphibian extinction. Conserv. Biol. 25, 956-964. doi: 10.1111/j.1523-1739.2011.01728.x

Quintero, I., and Wiens, J. J. (2013). Rates of projected climate change dramatically exceed past rates of climatic niche evolution among vertebrate species. Ecol. Lett. 16, 1095-1103. doi: 10.1111/ele.12144

Ricciardi, A., and Simberloff, D. (2009). Assisted colonization is not a viable conservation strategy. Trends Ecol. Evol. 24, 248-253. doi: 10.1016/j.tree.2008.12.006

Sandel, B., Arge, L., Dalsgaard, B., Davies, R. G., Gaston, K. J., Sutherland, W. J., et al. (2011). The influence of late Quaternary climate-change velocity on species endemism. Science 334, 660-664. doi: 10.1126/science.1210173

Sexton, J. P., Strauss, S. Y., and Rice, K. J. (2011). Gene flow increases fitness at the warm edge of a species' range. Proc. Natl. Acad. Sci. U.S.A. 108, 11704-11709. doi: 10.1073/pnas.1100404108

Shoo, L. P., Storlie, C., VanDerWal, J., Little, J., and Williams, S. E. (2011). Targeted protection and restoration to conserve tropical biodiversity in a 
warming world. Glob. Chang. Biol. 17, 186-193. doi: 10.1111/j.1365-2486.2010. 02218.x

Shoo, L. P., Storlie, C., Williams, Y. M., and Williams, S. E. (2010). Potential for mountaintop boulder fields to buffer species against extreme heat stress under climate change. Int. J. Biometeorol. 54, 475-478. doi: 10.1007/s00484-009-0286-4

Singhal, S., and Moritz, C. (2013). Reproductive isolation between phylogeographic lineages scales with divergence. Proc. R. Soc. Biol. Sci. 280:20132246. doi: 10.1098/rspb.2013.2246

Thomas, C. D., Cameron, A., Green, R. E., Bakkenes, M., Beaumont, L. J., Collingham, Y. C., et al. (2004). Extinction risk from climate change. Nature 427, 145-148. doi: 10.1038/nature02121

Umina, P., Weeks, A., Kearney, M., McKechnie, S., and Hoffmann, A. (2005). A rapid shift in a classic clinal pattern in Drosophila reflecting climate change. Science 308, 691-693. doi: 10.1126/science.1109523

VanDerWal, J., Murphy, H. T., Kutt, A. S., Perkins, G. C., Bateman, B. L., Perry, J. J., et al. (2013). Focus on poleward shifts in species' distribution underestimates the fingerprint of climate change. Nat. Clim. Chang. 3, 239-243. doi: $10.1038 /$ nclimate 1688

Weeks, A. R., Moro, D., Thavornkanlapachai, R., Taylor, H. R., White, N. E., Weiser, E. L., et al. (2015). "Conserving and enhancing genetic diversity in translocation programs," in Advances in Reintroduction Biology of Australian and New Zealand Fauna, eds D. Armstrong, M. Hayward, D. Moro, and P. Seddon (Canberra, ACT: CSIRO Publishing), 127.

Weeks, A. R., Sgrò, C. M., Young, A. G., Frankham, R., Mitchell, N. J., Miller, K. A., et al. (2011). Assessing the benefits and risks of translocations in changing environments: a genetic perspective. Evol. Appl. 4, 709-725. doi: $10.1111 / \mathrm{j} .1752-4571.2011 .00192 . \mathrm{x}$
Weiss, M. L., and Goodman, M. (1972). Frequency and maintenance of genetic variability in natural populations of Macaca fascicularis. J. Hum. Evol. 1, 41-48. doi: 10.1016/0047-2484(72)90040-1

Williams, S. E., Bolitho, E. E., and Fox, S. (2003). Climate change in Australian tropical rainforests: an impending environmental catastrophe. Proc. R. Soc. Biol. Sci. 270, 1887-1892. doi: 10.1098/rspb.2003.2464

Williams, S. E., and Pearson, R. G. (1997). Historical rainforest contractions, localized extinctions and patterns of vertebrate endemism in the rainforests of Australia’s wet tropics. Proc. R. Soc. Biol. Sci. 264, 709-716. doi: 10.1098/rspb.1997.0101

Williams, S. E., Shoo, L. P., Isaac, J. L., Hoffmann, A. A., and Langham, G. (2008). Towards an integrated framework for assessing the vulnerability of species to climate change. PLoS Biol. 6:60325. doi: 10.1371/journal.pbio.0060325

Willis, S. G., Hill, J. K., Thomas, C. D., Roy, D. B., Fox, R., Blakeley, D. S., et al. (2009). Assisted colonization in a changing climate: a test-study using two UK butterflies. Conserv. Lett. 2, 46-52. doi: 10.1111/j.1755-263X.2008. 00043.x

Conflict of Interest Statement: The authors declare that the research was conducted in the absence of any commercial or financial relationships that could be construed as a potential conflict of interest.

Copyright (C) 2017 Macdonald, Llewelyn, Moritz and Phillips. This is an open-access article distributed under the terms of the Creative Commons Attribution License (CC $B Y)$. The use, distribution or reproduction in other forums is permitted, provided the original author(s) or licensor are credited and that the original publication in this journal is cited, in accordance with accepted academic practice. No use, distribution or reproduction is permitted which does not comply with these terms. 